Article

\title{
Low-Molecular-Weight Phenols Recovery by Eco-Friendly Extraction from Quercus Spp. Wastes: An Analytical and Biomass-Sustainability Evaluation
}

\author{
Federica Ianni ${ }^{1,+}{ }^{\dagger}$ Enrico Segoloni ${ }^{2,+}{ }^{,}$Francesca Blasi ${ }^{1, *}$ (i) and Francesco Di Maria ${ }^{2,3, *(D)}$ \\ 1 Department of Pharmaceutical Sciences, University of Perugia, Via San Costanzo, 06126 Perugia, Italy; \\ federica.ianni@unipg.it \\ 2 LAR Laboratory-Engineering Department, University of Perugia, Via G. Duranti 93, 06125 Perugia, Italy; \\ enrico.segoloni@libero.it \\ 3 CIMIS Consortium, Via G. Duranti 67, 06125 Perugia, Italy \\ * Correspondence: francesca.blasi@unipg.it (F.B.); francesco.dimaria@unipg.it (F.D.M.); \\ Tel.: +39-075-585-7954 (F.B.); +39-075-585-3738 (F.D.M.) \\ + Federica Ianni and Enrico Segoloni equally contributed to this work.
}

Received: 3 March 2020; Accepted: 24 March 2020; Published: 26 March 2020

\begin{abstract}
In this work, chemical-physical protocols aimed at the implementation of eco-friendly and biomass-sustainable recovery processes of useful compounds from forestry and/or wood industry wastes were evaluated. Four species of interest in industrial and environmental fields (Quercus cerris, Quercus ilex, and Robinia pseudoacacia from Central Italy, Quercus petraea from France) were submitted to neutral extraction and analyzed by gaschromatography, with mass spectrometry identification of low-molecular-weight phenols. Moreover, Quercus petraea heartwood samples were submitted to three extraction/hydrolysis protocols in an alkaline environment, and the byproducts from the lignin degradation were identified and evaluated. The recovery of bioactive phenols from forestry wastes by applying eco-friendly extractive protocols may reveal a precious strategy for rethinking the management of such wastes, in line with the fundamentals of "circular economy".
\end{abstract}

Keywords: wood waste; mild extraction/hydrolysis protocols; lignin; phenolic compounds recovery; circular economy

\section{Introduction}

Oak wood, widely used by a variety of industries, is characterized by the presence of high levels of tannins of considerable scientific interest, besides their well-known practical value [1-6]. Phenolic compounds such as gallic acid, catechin, and epicatechin are notoriously endowed with antioxidants, astringents, and antimicrobial activity. Therefore, such species are subject of increasing interest in various fields such as pharmaceuticals, leather tanning, cosmetics, and the food industry [7-11]. Low-molecular-weight hydroxybenzoic acids and some of their derivatives can be obtained from wood extractives and via induced lignin degradation [12,13]. Lignin is a phenolic high-molecular-mass biopolymer, composed of a highly branched phenylpropanoid framework based on the three monomers coumaryl, coniferyl, and sinapyl alcohol. A number of other high-value fine chemicals such as vanillin, syringaldehyde, and $p$-coumaric, ferulic, $p$-hydroxybenzoic, syringic, and vanillic acids $[14,15]$ can be obtained among the various products of wood lignin degradation following de-polymerization processes (e.g., alkaline oxidation).

The recovery of molecules endowed with a biofunctional role from wood wastes, and their reuse and application in several fields, is one of the most challenging and promising actions in the circular economy domain. Based on the above facts, the possibility to improve (or implement new) standard 
chemical extraction/hydrolysis protocols to obtain organic compounds within a timber recycling context represents an issue of practical interest. The final goal is the individuation of mild, eco-friendly chemical and physical reaction conditions to achieve the compounds of interest [16]. A proper understanding of the distribution and structural features of extractives between bark, sapwood, and heartwood, as well as their variability in relative abundance between species, may have a significant impact on wood utilization $[17,18]$.

Sawdust wastes deriving from the Quercus petraea industrial manufacturing, and wooden wastes ofthe forestry activities derived from Quercus cerris, Quercus ilex, Quercus petraea, and Robinia pseudoacacia could be exploited as a source of useful compounds. Oak bark is the wood tissue richest in tannins, and $Q$. petraea bark is a source of gallic and ellagic acids as well as catechin and other tannin derivatives $[19,20]$. Typically, bark represents only the $10 \%-20 \%$ of the volume of a $\log$, so the sawdust-like wastes from heartwood manufacturing processes, combined with the woody wastes from forestry activities, could potentially represent a greater source for the recovery of the above-mentioned compounds. Moreover, sawdust produced by industrial heartwood treatment (sawmill processes) is much more suitable for extraction/hydrolysis processes compared to the byproducts of crude mechanical debarking. In addition, the lignin content of hardwoods like oaks amounts to about $25 \%-30 \%$ in weight [21], and represents the main potential source of useful organic compounds.

Heartwood from Q. petraea (Matt.) Liebl. (common name: French oak) is an interesting raw material, widely used in the industrial production of parquet, furniture, barrels for wine, and as a structural material in the construction industry, due to its excellent mechanical characteristics. It is also used as fuel for heating [22].

Q. cerris L. (common name: Turkey/Austrian oak) is not particularly valuable compared to the other Quercus species, due to its lack of tannins which makes it less durable. It is hard but not very resistant, and is used mainly as fuel.

Q. ilex L. (common name: Holm oak) has plenty of tannins and is a very resistant wood, but is difficult to work and to season. Therefore, it is primarily used for heating. Due to the richness of extractives, its bark is employed as a source of tannins for leather tanning [22]. Consequently, forestry activities wastes from these two "cheap" oak woods could become an important source of valuable chemical compounds.

R. pseudoacacia L. (common name: Black locust) is widely cultivated as a wood and honey-producing tree, with a high rate of development. This wood is used as a structural material as a substitute for some types of tropical wood in the production of parquet and, to some extent, of furniture [22]. Furthermore, it represents a substitute for oak wood in making containers in the cooperage industries $[5,6,23,24]$.

As previously outlined, the recovery and identification of such extractives currently represents an area of great interest for the development of renewable-resource-based systems. In this work, we focused on the chemical eco-friendly extraction, identification, and recovery of low-molecular-weight phenols obtainable from three species of oak heartwood: Q. cerris, Q. ilex (from Umbria region, Italy), and especially Q. petraea (from Fontaines, France). Moreover, the extractive analysis of R. pseudoacacia (from Umbria region, Italy) fresh bark/sapwood was also performed. The identification of low-molecular-weight phenols and the extract composition was assessed using a gas chromatography-mass spectrometry (GC-MS) system. Identification of trimethylsilyl derivatives (TMS derivatives) phenols from extracts was done by comparing the GC-MS profiles, retention times, and fragmentation patterns with those produced by the analysis of certified standards.

A further goal of the study was the evaluation of coniferyl and sinapyl alcohols, which are nominally the constituent monomers (monolignols) of the lignin structure in angiosperm species, as lignin degradation indicators. 


\section{Materials and Methods}

\subsection{Wood SampleCollection}

Heartwood from Q. cerris and Q. ilex trees, grown in the Umbria region (Central Italy), were taken after one year of natural seasoning. The $R$. pseudoacacia juvenile sample came from the same location $\left(43^{\circ} 6^{\prime} 43^{\prime \prime} \mathrm{N} ; 12^{\circ} 23^{\prime} 19^{\prime \prime} \mathrm{E}\right)$. The1 year naturally seasoned heartwood samples of $Q$. petraea came from Fontaines forest (Chalon-sur-Saône, France: $46^{\circ} 46^{\prime} 59^{\prime \prime} \mathrm{N} ; 4^{\circ} 51^{\prime} 0^{\prime \prime} \mathrm{E}$ ).

\subsection{Reagents and Standard Compounds}

Reference compounds used as standards are listed in Table 1. Coniferyl and sinapyl alcohols were synthesized according to the procedures reported in the literature [25]. Pure water was obtained using a Milli-Q Plus185 system from Millipore (Milford, MA, USA). Methanol (MeOH, $\geq 99.9 \%$ ), ethyl acetate $($ EtOAc, $\geq 99.9 \%)$, diethyl ether $\left(\mathrm{Et}_{2} \mathrm{O}, \geq 99.0 \%\right)$, tetrahydrofuran (THF, $\left.\geq 99.0 \%\right)$, hydrochloric acid $(\mathrm{HCl} ; \mathrm{w} / \mathrm{v} 37 \%)$, sodium hydroxide $(\mathrm{NaOH}, \geq 98.0 \%)$, anhydrous sodium sulphate $\left(\mathrm{Na}_{2} \mathrm{SO}_{4}, \geq 99.0 \%\right)$, pyridine ( $\geq 99.8 \%$ ), and the silylation agent N,O-bis(trimethylsilyl)trifluoroacetamide (BSTFA, $\geq 99.0 \%$ ), as well as reference phenolic standards (vanillin $\geq 99.0 \%$; $p$-hydroxybenzoic acid $\geq 99.0 \%$; syringaldehyde $\geq 98.0 \%$; vanillic acid $\geq 97.0 \%$; protocatechuic acid $\geq 97.0 \%$; syringic acid $\geq 95.0 \%$; gallic acid $\geq 99.0 \%$; ferulic acid $\geq 99.0 \%$; caffeic acid $\geq 98.0 \%$; (-)-epicatechin $\geq 98.0 \%$; (+)-catechin $\geq 98.0 \%$ ), were purchased from Sigma-Aldrich (Milan, Italy). All the reagents and standards used were of analytical grade.

Table 1. Characteristics MS fragments of phenols as TMS derivatives.

\begin{tabular}{ccccc}
\hline Identified Compounds & $\begin{array}{c}\text { Peak } \\
\text { Number }\end{array}$ & $\begin{array}{c}\text { Retention } \\
\text { Time (min) }\end{array}$ & $\begin{array}{c}\text { Molecular } \\
\text { Weight (g/mol) }\end{array}$ & m/z Values \\
\hline Vanillin & $\mathbf{1}$ & 12.65 & 224 & $193,194,209$ \\
p-Hydroxybenzoic acid & $\mathbf{2}$ & 14.33 & 282 & $193,223,267$ \\
Syringaldehyde & $\mathbf{3}$ & 15.91 & 254 & $195,224,239$ \\
Vanillic acid & $\mathbf{4}$ & 16.84 & 312 & $149,165,223,253,267,282,297$ \\
Protocatechuic acid & $\mathbf{5}$ & 17.87 & 370 & $193,223,267,311,355$ \\
(Z)-Coniferyl alcohol & $\mathbf{6}$ & 18.6 & 324 & $204,235,293,309$ \\
Syringic acid & $\mathbf{7}$ & 19.2 & 342 & $253,297,312,327$ \\
(E)-Coniferyl alcohol & $\mathbf{8}$ & 20.3 & 324 & $204,235,293,309$ \\
Gallic acid & $\mathbf{9}$ & 20.22 & 458 & $147,178,281,443,444$ \\
Dihydrosinapyl alcohol & $\mathbf{1 0}$ & 20.47 & 356 & $210,240,341$ \\
(Z)-Sinapyl alcohol & $\mathbf{1 1}$ & 20.6 & 354 & $204,323,339$ \\
Ferulic acid & $\mathbf{1 2}$ & 22.22 & 338 & $219,249,293,279,308,323$ \\
Caffeic acid & $\mathbf{1 3}$ & 22.85 & 396 & $179,191,219,381$ \\
(E)-Sinapyl alcohol & $\mathbf{1 4}$ & 22.47 & 354 & $204,323,339$ \\
(-)-Epicatechin & $\mathbf{1 5}$ & 29.94 & 650 & $147,267,355,357,368,369,370$ \\
(+)-Catechin & $\mathbf{1 6}$ & 30.04 & 650 & $147,267,355,368$ \\
\hline
\end{tabular}

MS, mass spectrometry; TMS, trimethylsilyl.

\subsection{Applied Extraction Protocols}

Based on previously optimized extraction/hydrolysis protocols [16] and experimental results, several parameters were properly tuned in order to maximize the yield of phenol extractions. This step was carried out by taking into account the polarity and the weak acid behavior of the investigated molecules. The use of high $\mathrm{pH}$ values proved to be suitable to increase compound solubility, while precipitation occurred at low values $(\mathrm{pH}<4-5)$. Other variables were then screened, such as extraction time and temperature and the fractionation solvent (diethyl ether vs. ethyl acetate). The obtained results allowed the following experimental conditions to be selected. From each sample, $10 \mathrm{~g}$ of sawdust (particle dimension $\leq 3 \mathrm{~mm}$ ) were mechanically derived. Two types of processes were performed: a NEP (Neutral Extraction Protocol) on all the four species, and EHPS (Extraction-Hydrolysis Protocols) in an alkaline environment, only applied on Q. petraea samples. Details are reported as follows. 


\subsubsection{NEP}

Samples were extracted via $300 \mathrm{~mL}$ of a MeOH/water $(1: 1, \mathrm{v} / \mathrm{v})$ neutral solution for $24 \mathrm{~h}$ at $25^{\circ} \mathrm{C}$, in darkness condition. Extracts were then filtered using a Büchner funnel (Whatman ${ }^{\circledR}$ grade 42 filter paper, from Sigma-Aldrich (Milan, Italy) and $\mathrm{MeOH}$ was removed at $35^{\circ} \mathrm{C}$. Next, the aqueous solutions were fractionated by liquid-liquid extractions with $\mathrm{Et}_{2} \mathrm{O}$ or $\mathrm{EtOAc}(30 \mathrm{~mL} \times 4)$ [26-28].

\subsubsection{EHPS}

Three samples $(10 \mathrm{~g})$ of $Q$. petraea (denoted as $A, B$, and $C$ ) were treated with $200 \mathrm{~mL}$ of a $1.5 \mathrm{M} \mathrm{MeOH} / \mathrm{NaOH}(1: 1, \mathrm{v} / \mathrm{v})$ solution under mechanical mixing at $50^{\circ} \mathrm{C}$, as follows:

$E H P-A$ : Sample $A$ was extracted and hydrolyzed for $72 \mathrm{~h}$. The extracts were filtered using a Büchner funnel and centrifuged to remove woody particles, then concentrated through a rotary evaporator at $35^{\circ} \mathrm{C}$ for $\mathrm{MeOH}$ removal. The aqueous solution ( $\mathrm{pH}$ 12.7) was neutralized by adding EtOAc $(60 \mathrm{~mL})$ and then acidified up to $\mathrm{pH} 1.0$ by $\mathrm{HCl}(12 \mathrm{~mL})$. After filtration and centrifugation for sodium acetate removal, the obtained acid solution was fractionated via liquid-liquid extractions with EtOAc $(25 \mathrm{~mL} \times 4)$;

EHP-B: Sample $B$ was extracted and hydrolyzed for $24 \mathrm{~h}$. After the woody particle and $\mathrm{MeOH}$ removal, the aqueous phase was acidified up to $\mathrm{pH} 1.0$ by $\mathrm{HCl}(10 \mathrm{~mL})$, and then fractionated with EtOAc $(25 \mathrm{~mL} \times 4)$;

EHP-C: Sample $C$ was extracted and hydrolyzed for $72 \mathrm{~h}$. After the woody particle and $\mathrm{MeOH}$ removal, the aqueous solution was acidified up to $\mathrm{pH} 1.0 \mathrm{by} \mathrm{HCl}(10 \mathrm{~mL})$. Acid phase was fractionated with $\mathrm{Et}_{2} \mathrm{O}(25 \mathrm{~mL} \times 4)$.

\subsection{GC-MS Apparatus}

GC analyses were performed on an Agilent 6850 Series gas chromatograph apparatus fitted with a splitless injector for a low background HP-5MS fused silica capillary column $(60 \mathrm{~m} \times 0.25 \mathrm{~mm}$ i.d., $0.25 \mu \mathrm{m}$ f.t.). Detection was achieved by a 5975B Mass single quadrupole spectrometer and the data were elaborated using a Chem Station software package (Agilent). The injector and detector temperatures were 250 and of $280^{\circ} \mathrm{C}$, respectively. The oven temperature gradient program was as follows: initial temperature of $90^{\circ} \mathrm{C}$ held for $1 \mathrm{~min}$; raised to $220^{\circ} \mathrm{C}$ (at $6{ }^{\circ} \mathrm{C} / \mathrm{min}$ ); raised to $290{ }^{\circ} \mathrm{C}$ (at $10^{\circ} \mathrm{C} / \mathrm{min}$ ) and held for $1.23 \mathrm{~min}$; and finally raised to $310^{\circ} \mathrm{C}$ (at $40^{\circ} \mathrm{C} / \mathrm{min}$ ) held for $7.5 \mathrm{~min}$. Helium was used as the carrier gas $(1.0 \mathrm{~mL} / \mathrm{min}$ flow rate). The injection volume was $1.0 \mu \mathrm{L}$. Electron impact ionization energy was $70 \mathrm{eV}$ and the system was scanned in a $140-465 \mathrm{~m} / \mathrm{z}$ mass range.

\subsection{Sample Preparation}

The organic fractions, dried at low pressure at $35^{\circ} \mathrm{C}$, were re-dissolved in a known quantity $(1.0 \mathrm{~mL})$ of the respective fractionation solvent by ultrasonic mixing. Finally, the compounds were submitted to a silylation procedure $[29,30]$. All reagents used in silylation were previously dehydrated by anhydrous $\mathrm{Na}_{2} \mathrm{SO}_{4}$, to avoid moisture interference with respect to the phenolic hydroxyl groups. Each $1 \mathrm{~mL}$ sample was transferred into a micro-vial and dried. Consequently, the residue was re-dissolved in $200 \mu \mathrm{L}$ of anhydrous EtOAc. A volume of $50 \mu \mathrm{L}$ of the silylation mixture (BSTFA-pyridine-EtOAc, 4:1:5, $\mathrm{v} / \mathrm{v} / \mathrm{v}$ ) was added and the whole solution was mechanically shaken for $1 \mathrm{~min}$ at room temperature. Before injection, samples were further diluted with $250 \mu \mathrm{L}$ of EtOAc.

\subsection{GC-MS Analysis}

Each extract was prepared in triplicate before being submitted to GC-MS determination. The obtained values were then used to calculate the global amount extracted from the initial $10 \mathrm{~g}$ samples according to Equation (1).

$$
(1 / 3) \times(\text { f.V. }) \times \sum \mathrm{df}_{\mathrm{i}}[\mathrm{X}]_{\mathrm{i}}, \mathrm{i}=1,2,3
$$


where (f.V.) is the final volume of the re-dissolved extracts, $\mathrm{df}_{\mathrm{i}}$ is the dilution factors, and $[\mathrm{X}]_{\mathrm{I}}$ is the concentrations in $\mathrm{mg} / \mathrm{mL}$ of the three $1 \mathrm{~mL}$ portions that underwent the silylation procedure.

Low-molecular-weight phenols were identified using certified standards and treated to give the TMS derivatives according to References [29,30], as described above. The fragmentation pattern obtained for each derivatized standard was first compared with data available in the literature [29-36]. The fragment ions of the selected peaks from the analysis of real samples were then identified and confirmed, based on the retention times and profile matching with signals from the corresponding standard (Table 1). Only the species that resulted pure through the "peak purity" response provided by the GC-MS software from the analysis of the real samples were submitted to quantitative evaluations. The quantitation was performed by injecting $1.0 \mu \mathrm{L}$ of the respective TMS standard solution at concentrations ranging from 0.02 to $0.50 \mathrm{mg} / \mathrm{mL}$ for ferulic acid and (-)-epicatechin, 0.04 to $1.00 \mathrm{mg} / \mathrm{mL}$ for syringaldehyde, vanillic acid, gallic acid, (E)-coniferyl alcohol, and (+)-catechin, and 0.2 to $5.0 \mathrm{mg} / \mathrm{mL}$ for vanillin. The method produced significantly linear (as indicated by the elevated $\mathrm{R}^{2}$ values $>0.99$ ) results in the explored ranges, and appreciably low LOD (limit of detection) and LOQ (limit of quantification) values were calculated for the investigated phenols (see Table S2 in Supporting Information for details).

\section{Results}

\subsection{Compounds Identified in the Investigated Arboreal Species}

Table 1 lists the identified compounds, while the mass spectral library matching is reported in Table S1 (Supporting Information). Tables 2 and 3 show the reproducibility of the NEP-EHPs peak areas for the quantified compounds (expressed as mean value $(n=3) \pm$ percentage standard deviation, \%SD). NEP extractions using EtOAc produced the best results in terms of number of identified species and peak purity, with respect to the EHPs. Hence, only the chromatographic data obtained using EtOAc as the fractionation solvent were considered (Figure 1).

Table 2. Peak areas (mean value $\pm \% S D$ ) for the NEP-quantified compounds $(n=3)$.

\begin{tabular}{cccccc}
\hline TMS Derivatives & $\begin{array}{c}\text { Peak } \\
\text { Number }\end{array}$ & Q.cerris & Q.ilex & R.pseudoacacia & Q. petraea \\
\hline Syringaldehyde & $\mathbf{3}$ & $9.53 \times 10^{5}( \pm 3.59 \%)$ & - & - & $1.56 \times 10^{7}( \pm 15.81 \%)$ \\
Vanillic acid & $\mathbf{4}$ & $1.18 \times 10^{7}( \pm 10.77 \%)$ & $9.45 \times 10^{6}( \pm 9.29 \%)$ & $1.16 \times 10^{7}( \pm 22.12 \%)$ & - \\
(E)-Coniferyl alcohol & $\mathbf{8}$ & $1.43 \times 10^{8}( \pm 37.01 \%)$ & $4.78 \times 10^{7}( \pm 5.69 \%)$ & $7.68 \times 10^{7}( \pm 21.96 \%)$ & $2.18 \times 10^{8}( \pm 18.36 \%)$ \\
Gallic acid & $\mathbf{9}$ & $2.70 \times 10^{7}( \pm 35.32 \%)$ & $3.21 \times 10^{7}( \pm 16.25 \%)$ & - & $5.60 \times 10^{8}( \pm 35.99 \%)$ \\
(-)-Epicatechin & $\mathbf{1 5}$ & $1.10 \times 10^{6}(\mathrm{u})$ & $3.81 \times 10^{6}( \pm 23.84 \%)$ & $6.51 \times 10^{6}( \pm 50.04 \%)$ & - \\
(+)-Catechin & $\mathbf{1 6}$ & $7.31 \times 10^{6}(\mathrm{u})$ & $3.62 \times 10^{8}( \pm 5.97 \%)$ & $4.27 \times 10^{7}( \pm 51.17 \%)$ & - \\
\hline
\end{tabular}

u: unambiguously detected only in one chromatogram; -: not detected.

Table 3. Peak areas (mean value $\pm \%$ SD) for the EHP-quantified compounds $(n=3)$.

\begin{tabular}{ccccc}
\hline TMS Derivatives & Peak Number & $\boldsymbol{E H P}-\boldsymbol{A}$ & $\boldsymbol{E H P}-\boldsymbol{B}$ & $\boldsymbol{E H P - C}$ \\
\hline Vanillin & $\mathbf{1}$ & - & - & $9.81 \times 10^{7}( \pm 29.30 \%)$ \\
Syringaldehyde & $\mathbf{3}$ & $1.06 \times 10^{7}( \pm 53.35 \%)$ & - & $6.95 \times 10^{8}( \pm 7.74 \%)$ \\
Vanillic acid & $\mathbf{4}$ & $3.12 \times 10^{8}( \pm 8.26 \%)$ & - & $2.48 \times 10^{8}( \pm 38.01 \%)$ \\
(E)-Coniferyl alcohol & $\mathbf{8}$ & $5.94 \times 10^{7}( \pm 17.76 \%)$ & $1.52 \times 10^{8}( \pm 55.13 \%)$ & $1.95 \times 10^{7}( \pm 33.29 \%)$ \\
Ferulic acid & $\mathbf{1 2}$ & $7.90 \times 10^{8}( \pm 3.55 \%)$ & - & - \\
\hline \multicolumn{5}{c}{}
\end{tabular}

NEP-extracted samples from $Q$. petraea were characterized by a substantial presence of gallic acid, which was also sufficiently abundant in Q. ilex, followed by Q. cerris (Table 2, Figure 1). In contrast, R. pseudocacia NEP and Q. petraea EHP extracts displayed no trace of this phenol compound.

Vichi et al. [32] reported the volatile components of oak wood chips analyzed by GC-MS without derivatization, as also reported for the analysis of other volatiles [37,38]. According to the literature [26,39], $p$-hydroxybenzoic acid, syringaldehyde, vanillic acid, protocatechuic acid, syringic 
acid, (E)-coniferyl alcohol, and (E)-sinapyl alcohol were identified in Q. petraea (Table S1, Supporting Information). The conspicuous amounts of (E)-coniferyl alcohol (Table 4) obtained by NEP and $E H P$ could be plausibly attributed to the ageing and to the induced process of lignin degradation, respectively (see Table S3 in Supporting Information for NEP/EHP yield comparisons with data reported in literature, and Figure S1 for synthesized coniferyl alcohol identification) [40].
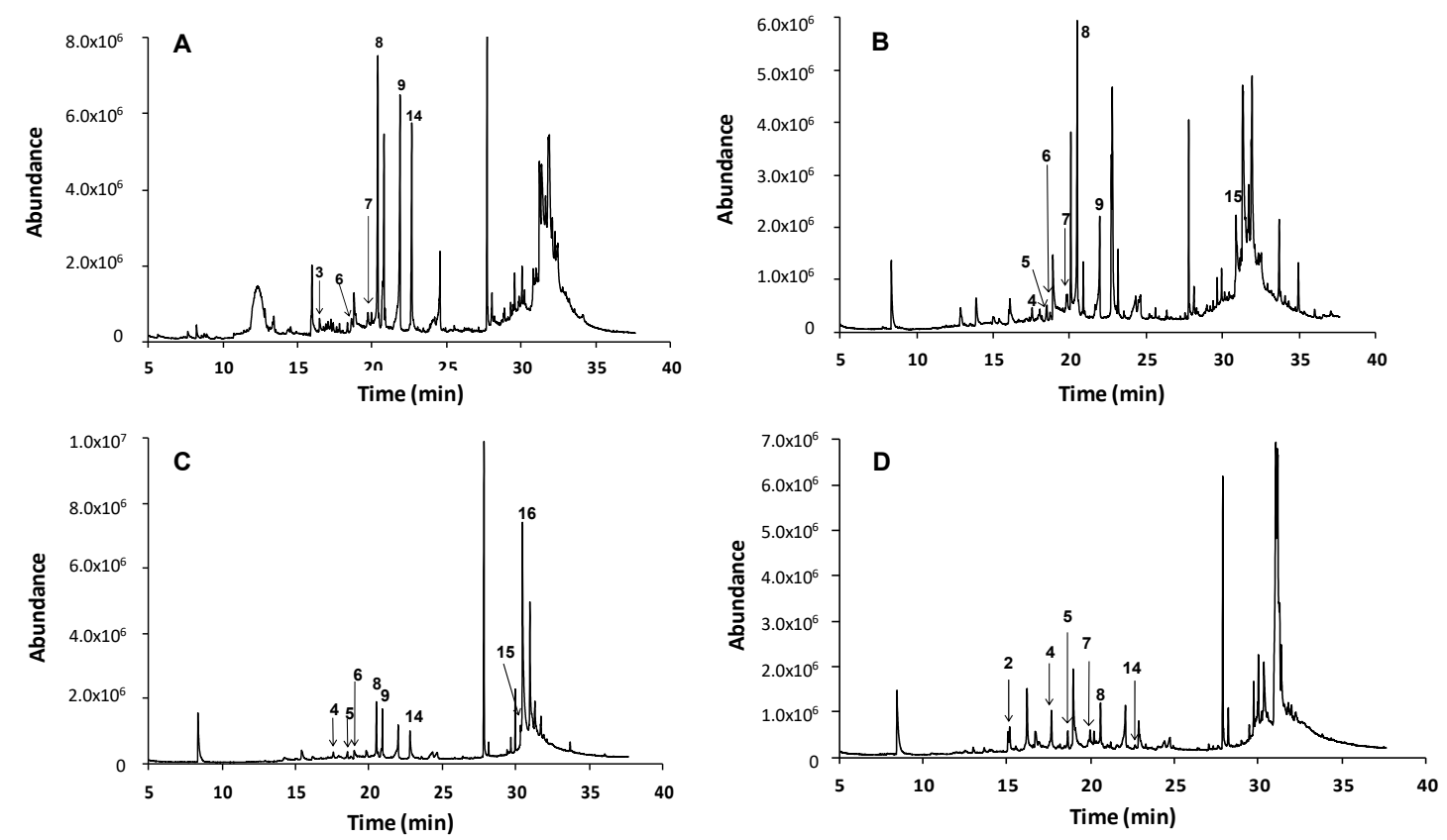

Figure 1. Profile according to NEP of (A) Q. petraea; (B) Q. cerris; (C) Q. ilex; (D) R. pseudoacacia. Peak numbers identify the compounds as reported in Table 1.

Table 4. TMS compound amounts $(\mathrm{mg})$ calculated with respect to the extracted mass $(10 \mathrm{~g})$.

\begin{tabular}{|c|c|c|c|c|c|c|c|}
\hline \multirow{2}{*}{$\begin{array}{c}\text { TMS } \\
\text { Derivatives }\end{array}$} & \multicolumn{7}{|c|}{ Amount in Wood Samples (mg/10 g) } \\
\hline & Q. cerris* & Q. ilex* & R.pseudoacacia* & Q. petraea* & Q. petraea ${ }^{\mathrm{a}}$ & Q. petraea ${ }^{\mathrm{b}}$ & Q. petraea ${ }^{\mathrm{c}}$ \\
\hline (+)-Catechin & 0.19 & 9.92 & 2.19 & - & - & - & - \\
\hline $\begin{array}{l}\text { (E)-Coniferyl } \\
\text { alcohol }\end{array}$ & 0.61 & 0.22 & 0.19 & 0.20 & 0.42 & 0.99 & 0.13 \\
\hline (-)-Epicatechin & - & 0.24 & 0.53 & - & - & - & - \\
\hline Ferulic acid & - & - & - & - & 15.96 & - & - \\
\hline Gallic acid & 0.09 & 0.26 & - & 1.14 & - & - & - \\
\hline Syringaldehyde & 0.01 & - & - & 0.02 & 0.17 & - & 7.40 \\
\hline Vanillic acid & 0.06 & - & 0.04 & - & 3.27 & - & 1.70 \\
\hline Vanillin & - & - & - & - & - & - & 0.55 \\
\hline
\end{tabular}

${ }^{*}$ by $N E P{ }^{\text {a }}$ by $E H P-A ;{ }^{\text {b }}$ by $E H P-B ;{ }^{\mathrm{c}}$ by $E H P-C ;-:$ not detected.

Low levels of gallic and vanillic acids were found in Q. cerris heartwood, while the highest concentration of $(E)$-coniferyl alcohol was found in this wood. $Q$. ilex was found to be rich in gallic acid, (+)-catechin, and (-)-epicatechin, as expected based on the literature data [41] (Table 2).

Qualitative identification of $(E)$-sinapyl alcohol was possible for $Q$. petraea and Q. cerris samples extracted by NEP. Moreover, this compound was identified in the $Q$. petraea extracts obtained according to protocols $E H P-B$ and $E H P-C$ (Table S1, Supporting Information). However, no quantitative evaluations of the sinapyl alcohol isomers were possible, due to the poor standard purity grade. Figure 2 shows typical chromatograms obtained from EHP from Q. petraea heartwood. Only the (E)-coniferyl alcohol was quantitatively determined on the extracts submitted to $E H P-B$ (time of reaction: $24 \mathrm{~h}$ ). $E H P-C$, based on the use of $\mathrm{Et}_{2} \mathrm{O}$, was the only protocol that allowed vanillin quantitation, while $E H P-A$ allowed the evaluation of ferulic acid. By comparing EHP-A and EHP-C with EHP-B results, the key 
role of the reaction time (72 vs. $24 \mathrm{~h}$ ) was clearly evident (Table 4). It is noteworthy that (E)-coniferyl alcohol was unambiguously identified and quantified in all the examined extract solutions.
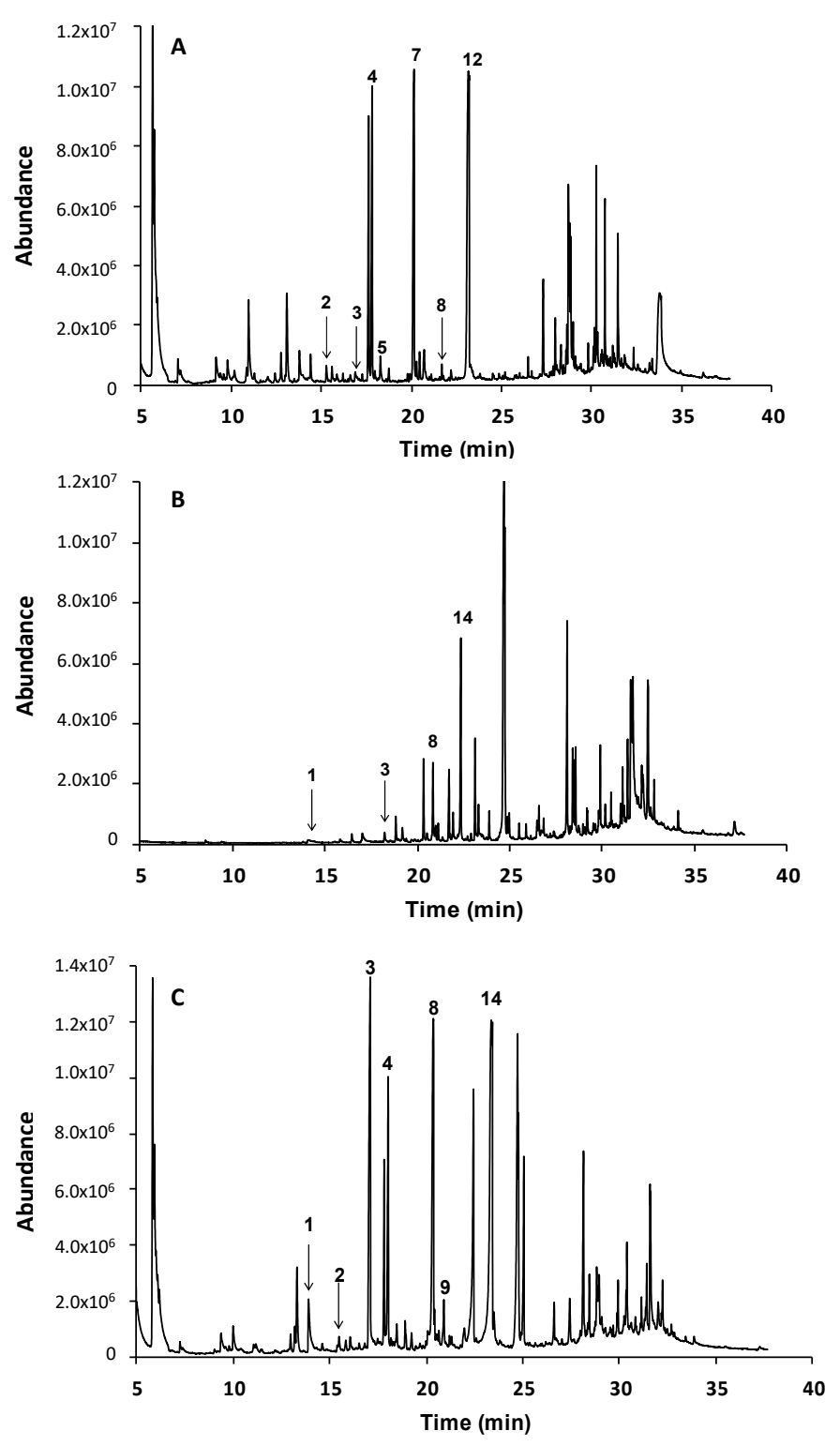

Figure 2. Profile of Q. petraea according to (A) EHP-A; (B) EHP-B; (C) EHP-C. Peak numbers identify the compounds as reported in Table 1.

The abundance of (+)-catechin and (-)-epicatechinin the younger tissues of R. pseudoacacia highlighted the potential for their recovery from forestry-activity-derived wastes. Moreover, the presence of quite a high level of $(E)$-coniferyl alcohol confirmed its biosynthetic origin. Accordingly, lignin biosynthesis implies the co-polymerization of the coniferyl and sinapyl alcohols [14,40]. In R. pseudoacacia extracts, caffeic, ferulic, protocatechuic, and vanillic acids were also detected, but only the last one was quantitatively evaluated (Table 4; Figure 1).

\subsection{Implementation of Eco-Friendly Extraction/Hydrolysis Protocols in the Forestry Waste Management Field}

Quantitative recovery of several useful compounds from Q. petraea lignin hydrolysis was achieved under mild chemical and physical conditions, with low concentrations of $\mathrm{NaOH}$, low reaction temperature $\left(50^{\circ} \mathrm{C}\right)$, and using solvents with a negligible toxic/environmental impact, except for $\mathrm{MeOH}$ 
which could be reasonably substituted by EtOH [42]. Moreover, air oxygen was the oxidizing agent used, and the prolonged reaction time, with strong mechanical mixing of the reaction solutions, was able to replace harsher reaction conditions. This approach was more ecofriendly than standard industrial processes carried out for the lignin treatment. Strong acid conditions used in EHP-A promoted significant formation of the ultimate oxidation products of coniferyl alcohol (ferulic and vanillic acids), whereas a weaker acidification, as in EHP-C, led to the prevalent formation of aldehydes (vanillin and syringaldehyde). As reported in Table 4, the EHP yields were influenced by the fractionation solvent. In fact, for instance, vanillin was freely soluble in $\mathrm{Et}_{2} \mathrm{O}$ (according to the EHP-C protocol), thus enabling its quantification.

The use of EtOAc in EHP-A to lower the $\mathrm{pH}$ caused its hydrolysis to $\mathrm{EtOH}$ and $\mathrm{NaOAc}$, which precipitates and hence could be easily separated. Interestingly, recovered $\mathrm{EtOH}$ could be reused as primary extraction solvent or, combined with the $\mathrm{AcOH}$ obtained via $\mathrm{HCl}$ acidification and $\mathrm{NaOAc}$, could regenerate EtOAc. The formation of EtOH during the EtOAc hydrolysis in an alkaline environment allows a solvent endowed with a middle polarity $(\varepsilon=26.0)$ to be used, on a scale where water is the most polar $(\varepsilon=80.1)$, and $\mathrm{AcOH}(\varepsilon=6.2)$ with EtOAc $(\varepsilon=6.0)$ represent the lower dielectric constants. Water/EtOH mixtures are commonly used to extract the most polar tannins, namely those with two or more hydroxyl groups and with a middle/high molecular weight [42,43]. EtOAc is suitable for phenols with a low polarity (generally with low molecular weight) and for huge nonpolar compounds.

Although mild lignin degradation conditions imply low yields, the target compounds were achieved in a more ecofriendly and energy-saving way, with respect to the traditional methods. Moreover, the use of wastes from forestry activities and of eco-friendly solvents allowed products not contaminated by unwanted/toxic chemicals to be obtained, in contrast to the byproducts from the Kraft and sulfite processes [15]. Additionally, the variety of obtainable substances could compensate their lower yields. Some simple forest resource planning could provide an overview of the potential exploitable biomasses achievable from the evaluated oaks' woods. For each species, the biomass obtainable from forestry management can be evaluated by the following relationship (Equation (2)).

$$
\mathrm{ABM}=\mathrm{SW} \times \mathrm{AABI} \times \mathrm{AFWC}
$$

where $\mathrm{ABM}(\mathrm{kg} /(\mathrm{ha} \times \mathrm{y}))$ is the available biomass $(\mathrm{kg})$ from a forest area of one hectare per year, $\mathrm{SW}$ $\left(\mathrm{kg} / \mathrm{m}^{3}\right)$ is the specific weight of the wood with a $12 \%$ content in weight of moisture, AABI $\left(\mathrm{m}^{3} /(\right.$ ha $\left.\times \mathrm{y})\right)$ is the average annual biomass increase, and AFWC (\%) is the average forestry waste coefficient, which indicates the percent rate of exploitable annual biomass. This parameter depends on factors such as forest type and management, age and type of logging, and especially on the final main use of the woody biomass.

In Central Italy's forestry management, Q. cerris, Q. ilex, and R. pseudoacacia are mainly exploited as firewood. This feature justifies the possible use of their biomasses for extractions. For Q. cerris and Q. ilex, Central Italian forest estimations provide an AFWC value of $17.5 \%$. The same value can be assumed for Q. petraea. Q. ilex's AABI is $3.5 \mathrm{~m}^{3} /$ ha, while a value of $3.0 \mathrm{~m}^{3} /$ ha is the lower limit for the other species. Considering the woody mass as heartwood, a first evaluation for ABMs and the achievable compounds is given in Table 5.

A possible industrial recovery cycle based on $E H P-A$ could be implemented to obtain phenols (low and high molecular weight) from lignin hydrolysis. By using $\mathrm{EtOH}$ instead of $\mathrm{MeOH}$ and $\mathrm{AcOH}$ instead of $\mathrm{HCl}$, the only net inputs would be $\mathrm{NaOH}$ and the energy required for the process. This energy could be obtained from the biomass itself, and the extracted wastes could be reused as energetic material. In addition, $\mathrm{EtOH}$ can be obtained by biomass fermentation. It is noteworthy that $\mathrm{NaCO}_{3} / \mathrm{KCO}_{3}$ "lye" solutions can be obtained (with low environmental impact) by settling or thermal treatment of woody ashes with water [40], and carbonate solutions could replace $\mathrm{NaOH}$ in the hydrolysis process. 
Table 5. Compounds yields (grams per hectare per year) and available biomass (ABM) values.

\begin{tabular}{|c|c|c|c|c|}
\hline TMS Derivatives & Q. cerris ${ }^{\mathrm{h}}$ & Q. ilex ${ }^{\mathrm{h}}$ & Q.petraea & R. pseudoacacias \\
\hline (+)-Catechin & 7.5 & 431.4 & - & 86.2 \\
\hline (E)-Coniferylalcohol & 43.9 & 9.6 & $44.2^{b}$ & 7.5 \\
\hline (-)-Epicathechin & - & 10.4 & - & 20.9 \\
\hline Ferulic acid & - & - & $712.2^{a}$ & - \\
\hline Gallic acid & 3.5 & 11.3 & $50.9^{\mathrm{h}}$ & - \\
\hline Syringaldeyde & 0.4 & - & $330.3^{c}$ & - \\
\hline Vanillic acid & 2.4 & - & $145.9^{\mathrm{a}}$ & 1.6 \\
\hline Vanillin & - & - & $24.5^{\mathrm{c}}$ & - \\
\hline $\begin{array}{l}\text { Specific weight } \\
\left(\mathrm{SW}, \mathrm{kg} / \mathrm{m}^{3}\right)\end{array}$ & 750 & 710 & 850 & 750 \\
\hline $\mathrm{ABM}, \mathrm{kg} /[\mathrm{ha} \times \mathrm{y}]$ & 393.7 & 434.9 & 446.3 & 393.8 \\
\hline
\end{tabular}

${ }^{\mathrm{h}}$ Heartwood by $N E P,{ }^{\mathrm{s}}$ sapwood-bark by $N E P ;^{\text {a }}$ heartwood by $E H P-A ;{ }^{\mathrm{b}}$ heartwood by $E H P-B ;{ }^{\mathrm{c}}$ heartwood by $E H P-C$; -: not detected.

With regard to NEP conditions, it should be underlined that "cheap" woods such as Q. ilex and R. pseudoacacia produced notable quantities of (+)-catechin and (-)-epicathechin under very mild conditions. The evaluations for R. pseudoacacia were based on a NEP sapwood/bark analysis, but young, branch-type woody wastes are also easily available as byproducts of the forestry activities. Moreover, the NEP quantifications did not account for high-molecular-weight phenols soluble in water/MeOH, which could be recovered by a global industrial process.

\section{Conclusions}

The main goal was the identification of the most suitable extraction conditions in terms of efficiency, eco-friendliness, and possibly low cost. The applied methods could potentially be extended to large-scale applications. This work showed the usefulness of NEP and especially of EHP in the treatment of woody wastes which, by mild and eco-friendly conditions, allowed

(i) the quantitative recovery by NEP of several naturally occurring valuable compounds ((+)-catechin, (E)-coniferyl alcohol, (-)-epicathechin, gallic acid, syringaldhehyde, and vanillic acid);

(ii) the possible implementation of an industrial cycle, particularly for the EHP-A protocol, justified by the estimated yields of (E)-coniferyl alcohol, ferulic acid, syringaldehyde, vanillic acid, and vanillin obtained from Quercus petraea heartwood samples.

The protocols described in the study allowed an analytical characterization of the bioactive compounds attainable from oak waste. The unambiguous GC-MS detection of $(E)$-coniferyl alcohol in all the analyzed samples provided the basis for implementation of a valuable method for the quantitative appraisal of the natural and alkali-induced lignin degradation processes.

This study lays the basis for future investigations aimed at the individuation of optimal and sustainable conditions for oak waste valorization, addressed at the recovery of precious bioactive molecules in the perspective of their applications in multiple industrial fields (pharmaceutical, textile, cosmetic, and food industries).

Supplementary Materials: The following are available online at http://www.mdpi.com/2227-9717/8/4/387/s1, Figure S1: GC-MS chromatogram and mass spectrum profile in EI mode at $70 \mathrm{eV}$ for the identification of the synthesized coniferyl alcohol (as TMS-derivative) [3,4]. Table S1: Mass spectral matching (\%) between the selected TMS-standards and the identified phenols in the extracts; Table S2: Explored linearity ranges, LOD and LOQ values for the investigated and identified phenols; Table S3: NEP/EHPs yields $(\mathrm{mg} / 10 \mathrm{~g})$ comparison with data reported in literature for Quercus petraea.

Author Contributions: F.D.M. conceived and supervised the project; F.I. and E.S. the extractions and GC-MS analyses and were involved in writing the manuscript; F.B. was involved in revising and editing the final paper. All authors approved the content of the submitted manuscript. All authors have read and agreed to the published version of the manuscript. 
Funding: This research received no external funding.

Acknowledgments: We wish to express our gratitude to Professor Roccaldo Sardella (Department of Pharmaceutical Sciences, University of Perugia, Italy) for his valuable suggestions and to Margaritelli s.p.a. Research and Development team (Moreno Gatti and Rinaldo Pernarella) for the Quercus petraea sample supply.

Conflicts of Interest: The authors declare no conflict of interest.

\section{References}

1. Eichhorn, S.; Erfurt, S.; Hofmann, T.; Seegmüller, S.; Németh, R.; Hapla, F. Determination of the phenolic extractive content in sweet chestnut (Castanea Sativa Mill.). Wood Res. 2017, 62, 181-196.

2. Chassaing, S.; Lefeuvre, D.; Jacquet, R.; Jourdes, M.; Ducasse, L.; Galland, S.; Grelard, A.; Saucier, C.; Teissedre, P.L.; Dangles, O.; et al. Physicochemical studies of new anthocyano-ellagitannin hybrid pigments: About the origin of the influence of oak C-glycosidic ellagitannins on wine color. Eur. J. Org. Chem. 2010, 2010, 55-63. [CrossRef]

3. Nunes, P.; Muxagata, S.; Correia, A.C.; Nunes, F.M.; Cosme, F.; Jordão, A.M. Effect of oak wood barrel capacity and utilization time on phenolic and sensorial profile evolution of an Encruzado white wine. J. Sci. Food Agric. 2017, 97, 4847-4856. [CrossRef]

4. Sefton, M.A.; Spillmann, P.J.; Pocock, K.F.; Francis, I.L.; Williams, P.J. The influence of oak origin, seasoning, and other industry practices on the sensory characteristics and composition of oak extracts and barrel-aged white wines. Aust. Grapegrow. Winemak. 1993, 355, 17-25.

5. Fernández de Simón, B.; Esteruelas, E.; Muñoz, Á.M.; Cadahía, E.; Sanz, M. Volatile compounds in acacia, chestnut, cherry, ash and oak woods, with a view to their use in cooperage. J. Agric. Food Chem. 2009, 57, 3217-3227. [CrossRef]

6. Sanz, M.; Fernádez de Simón, B.; Esteruelas, E.; Muñoz, Á.M.; Cadahía, E.; Hernández, M.T.; Estrella, I.; Martinez, J. Polyphenols in red wine aged in acacia (Robinia pseudoacacia) and oak (Quercus petraea). Anal. Chim. Acta 2012, 732, 83-90. [CrossRef]

7. Tresserra-Rimbau, A.; Lamuela-Raventos, R.M.; Moreno, J.J. Polyphenols, food and pharma. Current knowledge and directions for future research. Biochem. Pharmacol. 2018, 156, 186-195. [CrossRef]

8. Pucciarini, L.; Ianni, F.; Petesse, V.; Pellati, F.; Brighenti, V.; Volpi, C.; Gargaro, M.; Natalini, B.; Clementi, C.; Sardella, R. Onion (Allium cepa L.) Skin: A rich resource of biomolecules for the sustainable production of colored biofunctional textiles. Molecules 2019, 24, 634. [CrossRef]

9. Lisanti, A.; Formica, V.; Ianni, F.; Albertini, B.; Marinozzi, M.; Sardella, R.; Natalini, B. Antioxidant activity of phenolic extracts from different cultivars of Italian onion (Allium cepa) and relative human immune cell proliferative induction. Pharm. Biol. 2016, 54, 799-806. [CrossRef]

10. Burri, S.C.M.; Ekholm, A.; Håkansson, Å.; Tornberg, E.; Rumpunen, K. Antioxidant capacity and major phenol compounds of horticultural plant materials not usually used. J. Funct. Foods 2017, 38, 119-127. [CrossRef]

11. Caballero, A.S.; Romero-García, J.M.; Castro, E.; Cardona, C.A. Supercritical fluid extraction for enhancing polyphenolic compounds production from olive waste extracts. J. Chem. Technol. Biotechnol. 2020, 95, 356-362. [CrossRef]

12. Roffael, E. Significance of wood extractives for wood bonding. Appl. Microbiol. Biotechnol. 2016, 100, 1589-1596. [CrossRef] [PubMed]

13. Tanase, C.; Coșarcă, S.; Muntean, D.L. A Critical review of phenolic compounds extracted from the bark of woody vascular plants and their potential biological activity. Molecules 2019, 24, 1182. [CrossRef]

14. Brauns, F.E.; Brauns, D.A. The Chemistry of Lignin (Supplement Volume), 1st ed.; Academic Press Inc.: New York, NY, USA; London, UK, 1960.

15. Fache, M.; Boutevin, B.; Caillol, S. Vanillin production from lignin and its use as a renewable chemical. ACS Sustain. Chem. Eng. 2016, 4, 35-46. [CrossRef]

16. Segoloni, E.; Di Maria, F. UV-VIS spectral and GC-MS characterization of Handroanthus serratifolius (Vahl.) Grose (a.k.a. Tabebuiaserratifolia (Vahl.) Nichols/Lapacho) heartwood main extractives: A comparison of protocols aimed at a practical of lapachol and dehydro- $\alpha$-lapachone content. Eur. J. Wood Wood Prod. 2018, $76,1547-1561$. 
17. Miranda, I.; Sousa, V.; Ferreira, J.; Pereira, H. Chemical characterization and extractives composition of heartwood and sapwood from Quercus faginea. PLoS ONE 2017, 12, e0179268. [CrossRef]

18. Xiao, M.Z.; Chen, W.J.; Hong, S.; Pang, B.; Cao, X.F.; Wang, Y.Y.; Yuan, T.Q.; Sun, R.C. Structural characterization of lignin in heartwood, sapwood, and bark of eucalyptus. Int. J. Biol. Macromol. 2019, 138, 519-527. [CrossRef]

19. Azad, A.K.; Ogiyama, K.; Sassa, T. Isolation of (+)-catechin and a new polyphenolic compound in Bengal catechu. J. Wood Sci. 2001, 47, 406-409. [CrossRef]

20. Dedrie, M.; Jaquet, N.; Bombeck, J.; Hébert, P.L.; Richel, A. Oak barks as raw materials for the extraction of polyphenols for the chemical and pharmaceutical sectors: A regional case study. Ind. Crops Prod. 2015, 70, 316-321. [CrossRef]

21. Vivas, N.; Nonier, M.F.; Pianet, I.; Vivas de Gaulejac, N.; Fouquet, E. Structure of extracted lignins from oak heartwood (Quercus petraea Liebl., Q. Robur L.). Comptes Rendus Chim. 2006, 9, 1221-1233. [CrossRef]

22. Praciak, A. The CABI Encyclopedia of Forest Trees; CABI: Oxfordshire, UK, 2013.

23. Adamopoulos, S.; Voulgaridis, E.; Passialis, C. Variation of certain chemical properties within the stemwood of black locust (Robinia pseudoacacia L.). Holz Als Roh Und Werkst. 2005, 63, 327-333. [CrossRef]

24. Dünisch, O.; Richter, H.G.; Koch, G. Wood properties of juvenile and mature heartwood in Robinia pseudoacacia L. Wood Sci. Technol. 2010, 44, 301-313. [CrossRef]

25. Nascimento, R.I.; Lopes, L.M.X.; Davin, L.B.; Lewis, N.G. Stereoselective synthesis of 8,9-licarinediols. Tetrahedron 2000, 56, 9181-9193. [CrossRef]

26. Fernández de Simón, B.; Cadahìa, E.; Conde, E.; García-Vallejo, M.C. Low-molecular weight phenolic compounds in Spanish oak woods. J. Agric. Food Chem. 1996, 44, 1507-1511. [CrossRef]

27. Fernández de Simón, B.; Cadahìa, E.; Conde, E.; Garcia-Vallejo, M.C. Low-molecular weight phenolic compounds in woods of Spanish, French and American oak. J. Coop Sci. Technol. 1996, 2, 13-23.

28. Fernández de Simón, B.; Cadahìa, E.; Conde, E.; García-Vallejo, M.C. Evolution of phenolic compounds of spanish oak wood during natural seasoning. First results. J. Agric. Food. Chem. 1999, 47, 1687-1694. [CrossRef]

29. Zafra, A.; Juárez, M.J.B.; Blanc, R.; Navalón, A.; González, J.; Vílchez, J.L. Determination of polyphenolic compounds in wastewater olive oil by gas chromatography-mass spectrometry. Talanta 2006, 70, $213-218$. [CrossRef]

30. Lombardi, G.; Cossignani, L.; Giua, L.; Simonetti, M.S.; Maurizi, M.; Burini, G.; Coli, R.; Blasi, F. Phenol composition and antioxidant capacity of red wines produced in Central Italy changes after one-year storage. J. Appl. Bot. Food Qual. 2017, 90, 197-204.

31. Balaban, M. Identification of the main phenolic compounds in wood of Ceratonia siliqua by GC-MS. Phytochem. Anal. 2004, 15, 385-388. [CrossRef]

32. Vichi, S.; Santini, C.; Natali, N.; Riponi, C.; López-Tamames, E.; Buxaderas, S. Volatile and semi-volatile components of oak wood chips analysed by Accelerated Solvent Extraction (ASE) coupled to gas chromatography-mass spectrometry (GC-MS). Food Chem. 2007, 102, 1260-1269. [CrossRef]

33. Cossignani, L.; Luneia, R.; Damiani, P.; Simonetti, M.S.; Riccieri, R.; Tiscornia, E. Analysis of isomeric diacylglycerolic classes to evaluate the quality of olive oil in relation to storage conditions. Eur. Food Res. Technol. 2007, 224, 379-383. [CrossRef]

34. Kuroda, K.-I. Pyrolysis-trimethylsilylation analysis of lignin: Preferential formation of cinnamyl alcohol derivatives. J. Anal. Appl. Pyrol. 2000, 56, 79-87. [CrossRef]

35. Proestos, C.; Komaitis, M. Analysis of occurring phenolic compounds in aromatic plants by RP-HPLC coupled to diode array detector (DAD) and GC-MS after silylation. Foods 2013, 2, 90-99. [CrossRef] [PubMed]

36. Ribechini, E.; Zanaboni, M.; Raspolli Galletti, A.M.; Antonetti, C.; Nassi o Di Nasso, N.; Bonari, E.; Colombini, M.P. Py-GC/MS characterization of a wild and a selected clone of Arundodonax, and of its residues after catalytic hydrothermal conversion to high added-value products. J. Anal. Appl. Pyrol. 2012, 94, 223-229. [CrossRef]

37. Cossignani, L.; Giua, L.; Simonetti, M.S.; Blasi, F. Volatile compounds as indicators of conjugated and unconjugated linoleic acid thermal oxidation. Eur. J. Lipid Sci. Technol. 2014, 116, 407-412. [CrossRef]

38. Urbani, E.; Blasi, F.; Chiesi, C.; Maurizi, A.; Cossignani, L. Characterization of volatile fraction of saffron from central Italy (Cascia, Umbria). Int. J. Food Prop. 2015, 18, 2223-2230. [CrossRef] 
39. Cadahía, E.; Muñoz, L.; Fernádez de Simón, B.; García-Vallejo, M.C. Phenolic compounds of oak wood during seasoning and toasting. J. Agric. Food Chem. 2001, 49, 1790-1798. [CrossRef]

40. Sjöström, E. Wood Chemistry. Fundamentals and Applications, 2nd ed.; Academic Press: New York, NY, USA; London, UK, 1993.

41. Lavisci, P.; Scalbert, A.; Masson, D.; Janin, G. Quality of Turkey Oak (Quercus cerris L.) wood. I) Soluble and Insoluble Proanthocyanidins. Holzforschung 1991, 45, 291-296. [CrossRef]

42. Baeza, J.; Freer, J. Chemical characterization of wood and its components. In Wood and Cellulosic Chemistry, 2nd ed.; Hon, D.N.-S., Shiraishi, N., Eds.; Dekker: New York, NY, USA; Basel, Switzerland, 2001; pp. 275-384.

43. Umezawa, T. Chemistry of Extractives. In Wood and Cellulosic Chemistry, 2nd ed.; Hon, D.N.-S., Shiraishi, N., Eds.; Dekker: New York, NY, USA; Basel, Switzerland, 2001; pp. 213-241.

C 2020 by the authors. Licensee MDPI, Basel, Switzerland. This article is an open access article distributed under the terms and conditions of the Creative Commons Attribution (CC BY) license (http://creativecommons.org/licenses/by/4.0/). 